\title{
Techno-Economic Optimization and New Modeling Technique of PV-Wind-Reverse Osmosis Desalination Plant at Variable Load Conditions
}

\author{
Ahmed A. Hossam-Eldin, Kamal A. Abed, Karim H. Youssef, and Hossam Kotb
}

\begin{abstract}
In this paper, a new modeling technique of a seawater reverse osmosis (RO) desalination plant fed by hybrid renewable energy sources is provided. The proposed model consists of five sub-systems including RO plant model, photovoltaic (PV) model, horizontal wind turbine (HWT) model, battery model and the control room unit. In the RO model, the process is optimized to have the lowest specific energy consumption under different operating conditions and variable productivity ranging from 100 to $10000 \mathrm{~m}^{3}$ per day. However, in the PV and HWT models, various manufacturing datasheets for PV panels and wind turbines are stored at different power ratings. The model allows the selection of appropriate design specifications based on average solar radiation and average wind speed at the site. In addition, the total battery storage, Ampere-hour capacity and other specifications are calculated in the battery model. The control room unit is responsible for calculating the total annual costs and the cost of fresh water production according to the plant productivity, lifetime and interest rate. It has a splitter control ratio to regulate the load distribution between $P V$ and wind turbines relative to changes in climatic conditions. The model is simulated using Matlab/Simulink and provides good results for model validation.
\end{abstract}

Index Terms-Optimization, photovoltaic, reverse osmosis desalination, system modeling, wind turbine.

\section{INTRODUCTION}

The Middle East and North Africa (MENA) regions have the lowest per capita resources in the world in terms of water resources, but also the highest decline in these resources [1]. Fortunately, all countries in the MENA region have ample renewable energy potential that promotes the application of solar and/or wind technologies to supply desalination units. Fresh water production using desalination technologies driven by renewable energy systems is believed to be a vital solution to water scarcity in remote areas characterized by lack of drinking water and traditional energy sources such as heat and electricity networks [2].

Reverse osmosis (RO) has been developed in direct competition with distillation processes. Its main advantage is that it does not require heat energy, but mechanical energy is required in the form of a high-pressure pump (HPP). In the

Manuscript received March 28, 2019; revised May 23, 2019.

Ahmed A. Hossam-Eldin, Karim H. Youssef, and Hossam Kotb are with the Department of Electrical Engineering, Alexandria University, Alexandria, Egypt (e-mail: a.hossamudn@alexu.edu.eg, khmyoussef@yahoo.com, hossam.kotb@alexu.edu.eg).

Kamal A. Abed is with the Department of Mechanical Engineering, National Research Centre, Cairo, Egypt (e-mail: kaabed3@hotmail.com). past few years, RO water desalination technology has undergone remarkable transformation. The number and capacity of large RO plants have increased significantly. Systems with a capacity of up to $300,000 \mathrm{~m}^{3} / \mathrm{d}$ are currently under construction [3]. At the same time, renewable energy technologies have been widely distributed over the past few decades, particularly with desalination processes. Photovoltaic and/or wind energy are promising methods when dealing with desalination processes.

Kyriakarakos et al. [4] addressed the variable load energy management system based on fuzzy cognitive maps on reverse osmosis desalination. In order to evaluate the variable loading process, two case studies were studied through simulations. In both cases, the size of the PV system is initially determined by optimization for a desalination unit that operates only at full load. A renewable hybrid system has been introduced to produce domestic water consisting of a PV module, a wind turbine, a mechanical vapor compression desalination plant and a storage unit [5].

One of the main reasons for using RO instead of thermal distillation is the reliability and ease of combining directly with renewable energy resources such as solar and wind energies. Hossam-Eldin et al. [6] investigated the coupling of hybrid PV/wind energy sources with a reverse osmosis desalination plant to produce $1200 \mathrm{~m}^{3} / \mathrm{d}$. The water production unit cost was about $1.25 \$ / \mathrm{m}^{3}$ for power consumption of $280 \mathrm{~kW}$. The operation of reverse osmosis units was widely studied by Laissaoui et al. [7] in combination with various solar power plants, Concentrating Solar Power (CSP) and photovoltaic panels. Different configurations were assessed under variable loading conditions.

For small applications, Mohamed et al. [8] investigated technically and economically a photovoltaic system with a brackish water reverse osmosis desalination plant. The system was designed to produce an amount of $0.35 \mathrm{~m}^{3} / \mathrm{d}$ with a specific energy consumption of about $4.6 \mathrm{kWh} / \mathrm{m}^{3}$. Helal et al. [9] studied the economic feasibility of driving RO/PV under low power consumption. Three alternative formulations of an independent PV-RO unit were tested for remote areas in the UAE. It studied the possibility of using diesel generators for day-off periods. The PV-RO system was designed for not more than $20 \mathrm{~m}^{3} /$ day, but the work doesn't investigate the effect of diesel emissions on the environment. Manolakos et al. [10] presented some technical characteristics as well as an economic comparison of PV-RO desalination systems. The PV system consisted of $18 \mathrm{PV}$ panels with a total capacity of $846 \mathrm{~W}$. The system had a capacity of $0.1 \mathrm{~m}^{3} / \mathrm{h}$ and the specific 
energy consumption was in the range of $3.8-6 \mathrm{kWh} / \mathrm{m}^{3}$. However, the work doesn't investigate the large-scale production based on the PV power. Ahmed et al. [11], [12] designed a reverse osmosis desalination system with a small photovoltaic power scale. The cost of producing $1 \mathrm{~m}^{3}$ of fresh water using small-scale photovoltaic desalination systems was estimated at about $3.73 \$$.

Wind power is also used for this type of operation. Some of the literature in this section is provided for wind powered RO systems. Liu et al. [13] presented a wind-driven reverse osmosis system for aquaculture wastewater treatment. However, the economic analysis is not investigated. The operation of an experimental RO plant directly connected to the wind system was studied without energy storage by Pestana et al. [14]. The system was built to produce a quantity of $3.6 \mathrm{~m}^{3} / \mathrm{h}$ based on $21 \mathrm{~kW}$ power. Dehmas et al. [15] studied the availability of using the wind power for seawater reverse osmosis desalination plant.

Actually, different wind/RO plants capacities are ranged from 4-200 kW of nominal power for about a range of $12-2500 \mathrm{~m}^{3} / \mathrm{d}$ of desalted water [16], [17]. It is clear from the literature that the coupling of reverse osmosis plants with hybrid wind and PV energy sources is considered a promising solution to the energy crises.

The objective of this work is to provide a new technique for modeling a seawater RO system, which is fed by both PV and wind energy sources under variable load conditions ranging from 100 to $10,000 \mathrm{~m}^{3} /$ day. The RO model has been optimized under different operating conditions such as changing feed salinity and recovery ratio to minimize the total power consumption and the cost of water production. The model is provided with various manufacturing manuals for PV panels and horizontal wind turbines for simple and accurate simulation of renewable desalination systems. A control room unit is built in the model for cost analysis, overall system sizing and power switching between PV and HWT energy sources. The PV-HWT-RO model is validated by comparing the simulation results with the actual data of the desalination plant in Matrouh, Egypt [6] as a case study. The comparison show good results for power consumption, SEC and unit product cost.

\section{SYSTEM DESCRIPTION AND MODELING}

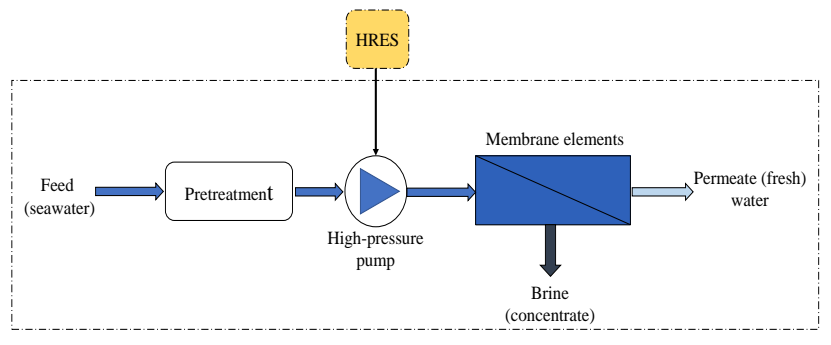

Fig. 1. A schematic diagram of the reverse osmosis process fed from the HRES.

The schematic diagram of the reverse osmosis process is shown in Fig. 1. The system consists of pre-treatment filters that remove all suspended solids from the feed water stream to correspond to membrane conditions. The most important phase in this process is the pressure stage. At this stage, the feed pressure is increased to the appropriate level of membranes using the high-pressure pump (HPP), which ranges from 30 to 80 bar in the case of high feed salinity. Since the power consumption by the HPP is relatively high, an optimization model will be introduced in the next section to reduce the specific energy consumption (SEC). The HPP is fed from a hybrid renewable energy source (HRES) which is described in Fig. 2. Based on productivity, the plant is designed with a certain number of pressure vessels containing membrane elements. The hybrid energy source consists of PV panels, horizontal wind turbines (HWT), battery bank and converter. The size of PV panels, wind turbines and batteries is calculated using the PV-HWT-RO model as well as the total annual costs of the plant and the cost of producing fresh water with different plant capacities from 100 to $10000 \mathrm{~m}^{3}$ per day. As shown in Fig. 3, the PV-HWT-RO model consists of five major sub-systems with the following characteristics:

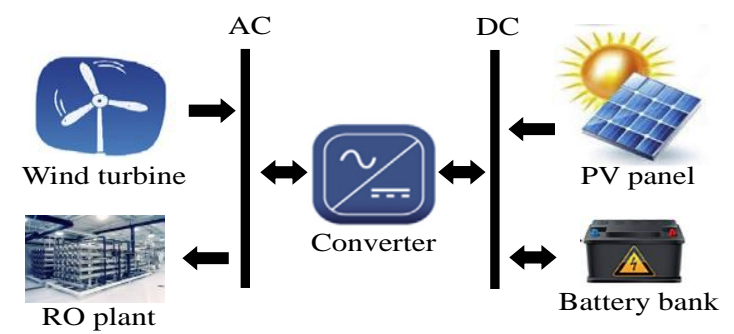

Fig. 2. A schematic diagram of the hybrid renewable energy source supplying the RO plant.

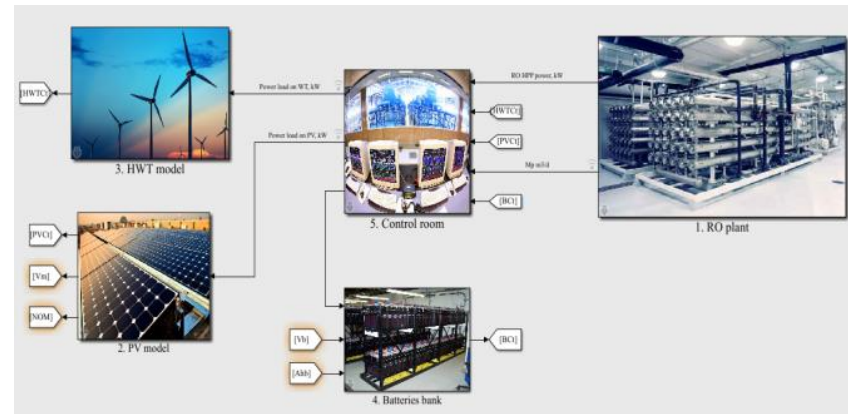

Fig. 3. PV-HWT-RO simulation model using Matlab/Simulink.

- RO plant model: In this model, the productivity ranges from 100 to $10000 \mathrm{~m}^{3} /$ day. The operating conditions, salinity, membrane type, recovery ratio, HPP efficiency, number of pressure vessels, number of membrane elements per vessel and other design criteria are determined. The model determines the power consumption by the HPP, the specific energy consumption and the required applied pressure across the membranes.

- PV model: In this model, various manufacturing manuals (over 500 datasheets) are stored with different PV power ratings of $50 \mathrm{~W}$ to $320 \mathrm{~W}$. The model allows the selection of appropriate PV panels and gives the main specifications based on the average solar radiation such as open circuit voltage, short circuit current, voltage at maximum power, current at maximum power, module efficiency and cost.

- HWT model: The horizontal wind turbine model design is similar to the PV model design. The model is provided with more than 400 datasheets from different manufactures worldwide. The user can adjust the unit 
power from $1 \mathrm{~kW}$ to $50 \mathrm{~kW}$ and the average wind speed, then the model determines the main specifications of the selected wind turbine. These specifications include cut-in wind speed, rated speed, rotor diameter, rotor speed, hub height, rated voltage and unit cost.

- Batteries bank: This model calculates the battery Wh storage, the battery Ah capacity and the number of batteries according to the battery voltage, efficiency, depth of discharge and battery cost.

- Control room unit: This unit is responsible for calculating the total annual costs of RO plant, PV panels, wind turbines and batteries according to the productivity, plant life time and interest rate. It also calculates the unit product cost in $\$ / \mathrm{m}^{3}$ of fresh water and regulates the load distribution between PV and wind turbines. It has a splitter ratio from 0 to 1 while 0 means full loaded on PV and 1 means full loaded on WT. The splitter ratio can be controlled to show the load power fluctuations on both PV and WT relative to weather conditions variation. The PV-HWT-RO model is built and simulated using Matlab/Simulink.

\section{A. Reverse Osmosis Mathematical Model [2], [7]}

The feed flow rate to reverse osmosis membranes can be expressed by the following equation

$$
M_{f}=M_{p} / R R .
$$

where $M_{f}, M_{p}$ and $R R$ are the feed flow rate, permeate flow rate and recovery ratio, respectively. The fresh water (permeate) salinity is expressed by

$$
X_{p}=\left(K_{s} \times A_{t} \times X_{a v}\right) / M_{p} .
$$

where $X_{p}, k_{s}, A_{t}$ and $X_{a v}$ are the permeate salinity, salt permeability, total membrane area and average salinity, respectively. The salt permeability is given by

$$
\begin{aligned}
K_{s}= & 4.72 \times 10^{-7} \times F F \times T C F \times\left(0.062-\left(5.3 \times 10^{-5}\right.\right. \\
& \left.\left.\times\left(T_{\text {sea }}+273\right)\right)\right) .
\end{aligned}
$$

where $k_{s}, F F, T C F, T_{\text {sea }}$ are the salt permeability, the membrane fouling factor, the temperature correction factor and seawater temperature, respectively. The temperature correction factor $T C F$ is calculated by

$$
T C F=\exp \left(3020 \times\left(1 /\left(273+T_{\text {sea }}\right)-1 / 298\right)\right) .
$$

The concentrate (brine) flow rate can be calculated as

$$
M_{c}=M_{f}-M_{p} .
$$

where $M_{c}$ is the brine flow rate. The rejected salt concentration can be determined by

$$
X_{c}=\left(M_{f} \times X_{f}-M_{p} \times X_{p}\right) / M_{c} .
$$

where $X_{c}, X_{f}$ are the concentrate and feed salt concentration, respectively. The membrane water permeability $k_{w}$ is calculated by

$$
\begin{aligned}
K_{w}= & 6.84 \times 10^{-8} \times\left(18.685-\left(0.177 \times X_{c}\right) /\right. \\
& \left.\left(T_{\text {sea }}+273\right)\right) .
\end{aligned}
$$

The net pressure difference across the membrane $\Delta \mathrm{P}$ is expressed by

$$
\Delta P=M_{p} /\left(T C F \times K_{w} \times F F \times A_{e} \times N_{e} \times N_{v}\right)+\Delta \pi .
$$

where $A_{e}, N_{e}, N_{v}$ and $\Delta \pi$ are the membrane element area, number of membrane elements per vessel, number of pressure vessels and the net osmotic pressure across the membrane, respectively. The required power input for the RO high-pressure pump $\mathrm{P}_{\mathrm{RO}}$ is given by

$$
P_{R O}=\left(0.2777 \times M_{f} \times \Delta P\right) /\left(\rho \times \eta_{h p p}\right) .
$$

where $\rho$ and $\eta_{h p p}$ are the feed water density and the high-pressure pump efficiency, respectively. Finally, the specific energy consumption of the RO plant is calculated by

$$
S E C=\left(P_{R O} \times 24\right) / M_{p} .
$$

\section{B. RO Optimization Model Formula}

The objective of the RO optimization model shown in Fig. 4 is to minimize the total power consumption by the RO high-pressure pump and the specific energy consumption of the plant which in turn will reduce the overall costs and fresh water production cost.

Minimize $P_{R O}$ and $S E C=\operatorname{function}\left(M_{p}, \Delta P\right.$,

Subject to

$$
\begin{gathered}
100 \leq M_{p} \leq 10000 \\
30000 \leq X_{f} \leq 45000 \\
0.15 \leq R R \leq 0.5 \\
1 \leq N_{v} \leq 300 \\
50 \leq X_{p} \leq 300 \\
30 \leq \Delta P \leq 60
\end{gathered}
$$

The following design variables are supposed to be fixed as following

$$
\begin{aligned}
& N_{e}=6, A_{e}=35 \mathrm{~mm}^{2}, F F=0.85, \eta_{h p p}=0.85, \\
& \rho=1030 \mathrm{~kg} / \mathrm{m}^{3} \text { and } T_{\text {sea }}=20^{\circ} \mathrm{C}
\end{aligned}
$$

\section{Proposed PV-HWT Model}

The proposed PV model is provided through various manufacturing manuals (over 500 datasheets) with a different module power rating of $50 \mathrm{~W}$ to $320 \mathrm{~W}$. As shown in Fig. 5, the user can assign the required PV power rating $P_{m}$ and the average solar irradiance $\emptyset_{S}$, then the model will determine the main characteristics of the specified panel such as open circuit voltage $V_{O C}$, short circuit current $I_{s c}$, voltage at maximum power $V_{m p}$, current at maximum power $\mathrm{I}_{\mathrm{mp}}$, module efficiency $\eta_{m}$ and $\operatorname{cost} C_{m}$. In addition, the total number of PV modules $N_{m}$ can be calculated as

$$
N_{m}=P_{P V} / P_{m}
$$

where $P_{P V}$ and $P_{m}$ are the total PV power and module power, 
respectively.

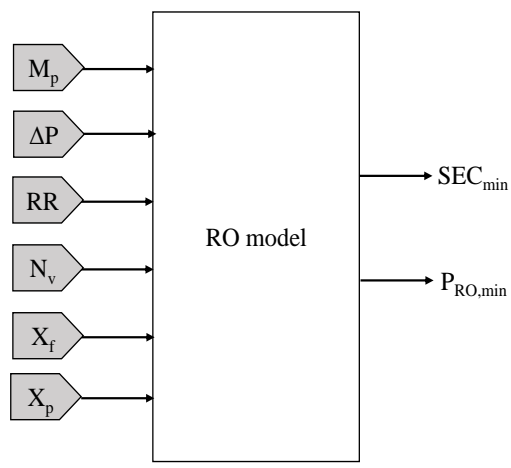

Fig. 4. RO model block diagram.

Moreover, the wind turbine model design is similar to the PV model design. The model is stored with more than 400 datasheets from different manufactures worldwide. The user can adjust the unit power $P_{u}$ from $1 \mathrm{~kW}$ to $50 \mathrm{~kW}$ and the average wind speed in the site $v_{a v}$ as shown in Fig. 6, then the model sets the main specifications of the selected wind turbine. These specifications include cut-in wind speed, rated wind speed, rotor diameter, rotor speed, hub height, rated voltage and unit cost. The total number of wind turbines $N_{u}$ can be calculated from

$$
N u=P_{W T} / P_{u} .
$$

where $P_{W T}$ and $P_{u}$ are the total wind power and turbine unit power, respectively. Regarding the battery design, the total battery storage $B S_{t}$ can be calculated by

$$
B S_{t}=\left(P_{t} \times O H \times N_{a}\right) /\left(D O D \times \eta_{b}\right) .
$$

where $P_{t}, O H, N_{a}, D O D$ and $\eta_{b}$ are the total power consumption, operating hours per day, number of autonomy days and battery efficiency, respectively. The total batteries Ampere-hour $A h_{t}$ can be calculated by

$$
A h_{t}=B S_{t} / V_{b}
$$

where $V_{b}$ is the battery voltage. Then, the total number of batteries $N_{b}$ can be calculated by

$$
N_{b}=A h_{t} / A h_{b} \text {. }
$$

where $A h_{b}$ is the battery Ampere-hour capacity. Finally, the power distribution on PV and WT can be expressed as

$$
\begin{gathered}
P_{P V}=(1-s p l) \times P_{t} . \\
P_{W T}=s p l \times P_{t} .
\end{gathered}
$$

where $s p l$ is the splitter ratio which ranges from 0 to 1 . When $(s p l=0)$, this means that the RO plant is fully supplied by PV and when $(s p l=1)$, this means that full wind power is provided. The splitter ratio can be controlled to show the load variation on both PV and WT relative to weather conditions variation.

\section{Cost Analysis of the PV-HWT-RO System [18]}

The direct capital cost of the RO plant $C_{D}$ can be estimated by the following equation

$$
C_{D}=(500 \approx 1000) \times M_{p} .
$$

The cost of membrane elements purchase $C_{M}$ can be estimated by

$$
C_{M}=(50 \% \approx 60 \%) \times C_{D} .
$$

The annual replacement cost of membrane elements $C_{M R}$ can be estimated by

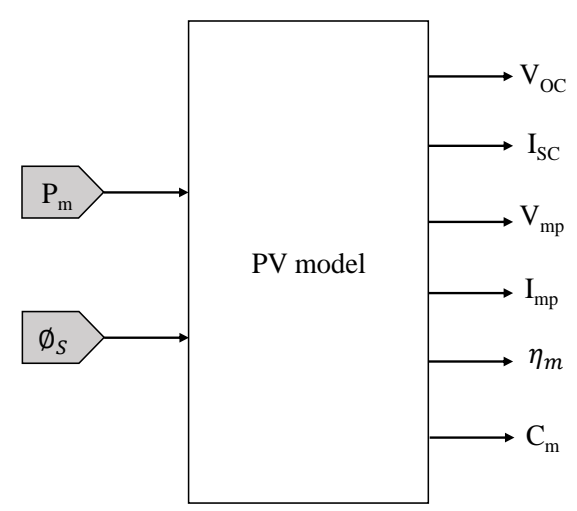

Fig. 5. PV model block diagram.

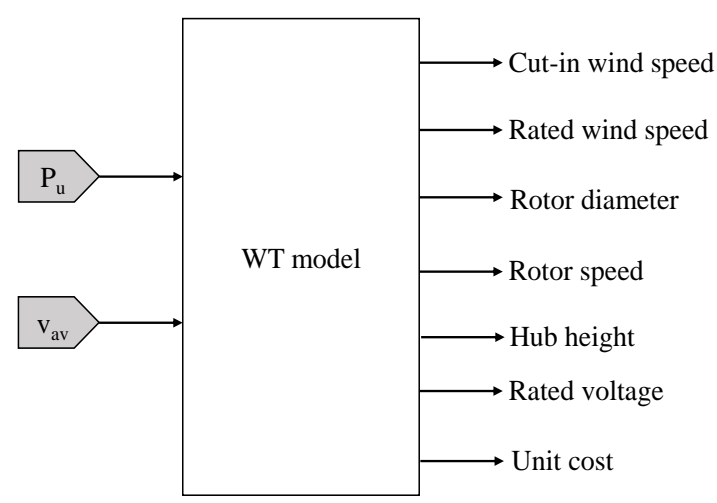

Fig. 6. Wind turbine model block diagram.

$$
C_{M R}=(10 \% \approx 30 \%) \times C_{M} .
$$

The amortization factor $A F$ is calculated by

$$
A F=\left(i \times(1+i)^{n}\right) /\left((1+i)^{n}-1\right) .
$$

where $i$ and $n$ are the interest rate and the plant life time, respectively. The annual fixed charges $C_{F}$ can be estimated by

$$
C_{F}=A F \times C_{D} .
$$

The annual PV costs $C_{P V}$ can be calculated by

$$
C_{P V}=C_{m} \times N_{m} \times A F .
$$

where $C_{m}$ and $N_{m}$ are the PV module cost and the number of PV modules, respectively. The annual WT costs $C_{W T}$ can be calculated by

$$
C_{W T}=C_{u} \times N_{u} \times A F .
$$

where $C_{u}$ and $N_{u}$ are the cost of wind turbine unit and the number of wind turbines, respectively. The annual total batteries cost $C_{T B}$ is calculated by

$$
C_{T B}=C_{b} \times N_{b} \times A F .
$$

where $C_{b}$ and $N_{b}$ are the battery unit cost and number of batteries, respectively. The annual total costs of the plant $\mathrm{C}_{\mathrm{t}}$ can be calculated by 


$$
C_{t}=C_{M R}+C_{F}+C_{P V}+C_{W T}+C_{T B}+C_{O \& M} .
$$

where $C_{O \& M}$ is the annual operation and maintenance cost of the plant. Finally, the unit water product $\operatorname{cost} C_{w}$ can be calculated by

$$
C_{W}=C_{t} /\left(M_{p} \times L F \times 365\right) .
$$

where $L F$ is the load factor of the plant. All the above cost equations can be simulated in the control room subsystem at different plant capacities from 100 to $10000 \mathrm{~m}^{3} /$ day. The system is designed and simulated using Matlab/Simulink assuming $L F=0.85, i=0.05$ and $n=20$ years.

\section{Simulation Results AND Discussions}

\section{A. Effect of Varying the Recovery Ratio}

By increasing the recovery ratio from 0.15 to 0.5 , the SEC decreases from 7.6 to $3.2 \mathrm{kWh} / \mathrm{m}^{3}$ as shown in Fig. 7(a) and the power consumed by RO-HPP is reduced from 32 to $14 \mathrm{~kW}$ as shown in Fig. 7(b) at $M_{p}=100 \mathrm{~m}^{3} / \mathrm{d}, N_{v}=2$ and feed salinity of $30000 \mathrm{ppm}$. While the net pressure across membranes increases from 36 to 51 bar as described in Fig. $7(\mathrm{c})$, and the fresh water salinity also increases from 220 to $265 \mathrm{ppm}$. Therefore, the recovery ratio should not be significantly increased to keep $\Delta \mathrm{P}$ and $X_{p}$ within limits.

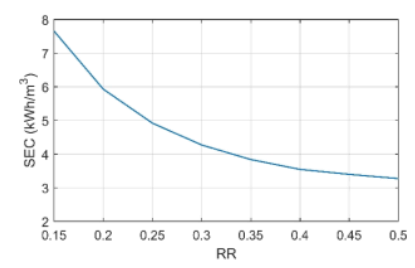

(a)

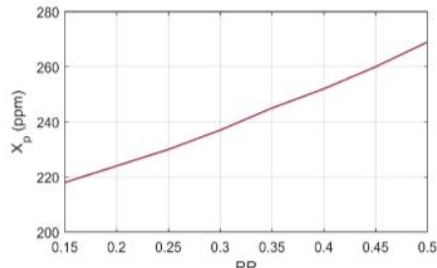

(c)
Fig. 7. Effect of varying RR on (a) $\mathrm{SEC}$ (b) $\mathrm{P}_{\mathrm{RO}}$ (c) $\Delta \mathrm{P}$ and (d) $X_{\mathrm{p}}$ at $M_{p}=100$ $\mathrm{m}^{3} / \mathrm{d}, N_{v}=2$ and $X_{f}=30000 \mathrm{ppm}$.

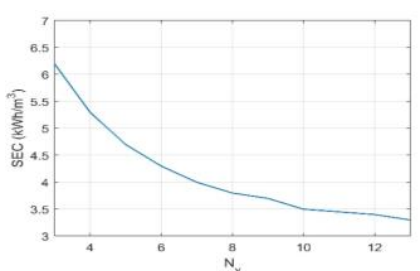

(a)

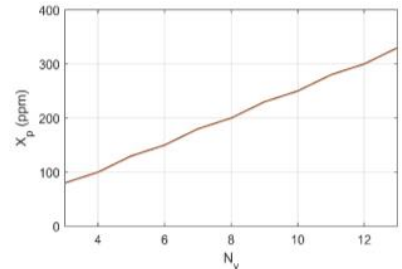

(c)

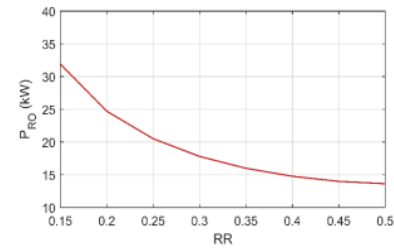

(b)

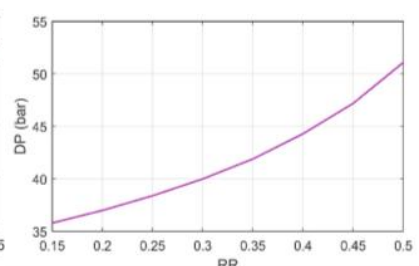

(d)

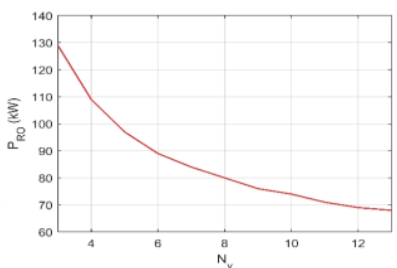

(b)

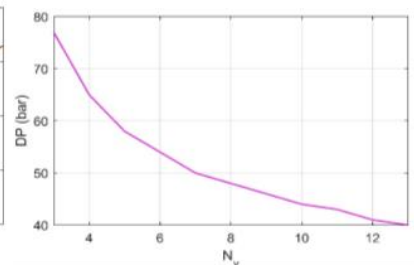

(d)

Fig. 8. Effect of varying $N_{v}$ on (a) $\mathrm{SEC}$ (b) $\mathrm{P}_{\mathrm{RO}}$ (c) $\Delta \mathrm{P}$ and (d) $X_{p}$ at $M_{p}=500$ $\mathrm{m}^{3} / \mathrm{d}, R R=0.4$ and $X_{f}=30000 \mathrm{ppm}$.

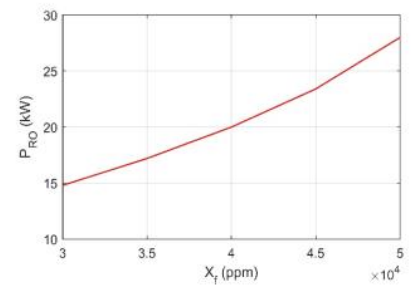

(a)

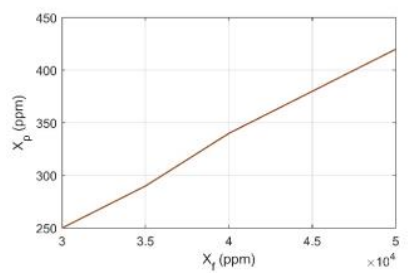

(c)

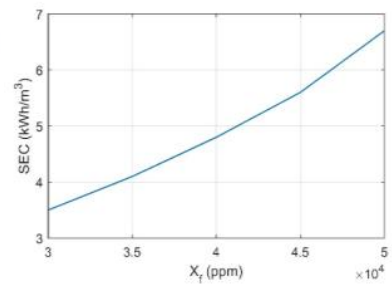

(b)

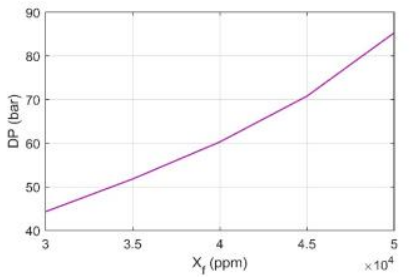

(d)
Fig. 9. Effect of varying $X_{f}$ on (a) SEC (b) $\mathrm{P}_{\mathrm{RO}}$ (c) $\Delta \mathrm{P}$ and (d) $X_{p}$ at $M_{p}=100$ $\mathrm{m}^{3} / \mathrm{d}, N_{v}=2$ and $R R=0.4$.

\section{B. Effect of Varying the Number of Pressure Vessels}

By increasing the number of pressure vessels, both SEC and power consumption are reduced to $3.5 \mathrm{kWh} / \mathrm{m}^{3}$ and 70 $\mathrm{kW}$, respectively as shown in Fig. 8(a) and Fig. 8(b). This is due to the reduction in feed pressure with the increase of vessels as shown in Fig. 8(c). However, it can be observed that the permeate salinity $X_{p}$ increases by increasing $N_{v}$ as shown in Fig. 8(d). So, the optimum number of vessels will be obtained from the optimization model design of the RO at different plant capacities in order to maintain salinity within the limits (less than $300 \mathrm{ppm}$ ) and have the lowest SEC.

\section{Effect of Varying the Feed Salinity}

Fig. 9(a) and 9(b) show the effect of increasing seawater salinity from $30,000 \mathrm{ppm}$ to $50,000 \mathrm{ppm}$ on SEC and HPP power consumption at $100 \mathrm{~m}^{3} / \mathrm{d}$ productivity. The SEC increases from $3.5 \mathrm{kWh} / \mathrm{m}^{3}$ at $X_{f}=30000 \mathrm{ppm}$ to $6.7 \mathrm{kwh} / \mathrm{m}^{3}$ at $50000 \mathrm{ppm}$ of feed salinity. The power consumption also increases from $15 \mathrm{~kW}$ to $30 \mathrm{~kW}$, where HPP requires high pressure to drive the highest salt water through membranes.

Fig. 9(c) and 9(d) illustrate that feed pressure and permeate salinity have a significant increase at higher feed salinity. Moreover, the SEC can be reduced by increasing $N_{v}$ or decreasing RR. So, optimum values for $N_{v}$ and RR are calculated at different feed salinities.

\section{Optimization Results of RO Model}

The results of the optimum values of number of pressure vessels $N_{v}$, power consumption by RO-HPP and SEC are shown in Fig. 10 based on the constraints of $100 \leq M_{p} \leq 1000$ $\mathrm{m}^{3} / \mathrm{d}, 0.15 \leq R R \leq 0.5$ and $X_{f}=30000 \mathrm{ppm}$. The optimum number of pressure vessels ranges from 2 to 28 as shown in Fig. 10(a) of a plant capacity ranging from 100 to 1000 $\mathrm{m}^{3} /$ day. It can be observed that by increasing the recovery ratio at a certain productivity, the number of vessels will be reduced to maintain pressure and permeate salinity within the required limits. With the increase in RR, a slight decrease in both power consumption and SEC occurs at small capacity, while a relative decrease occurs at high capacity as shown in Fig. 10(b) and Fig. 10(c). Finally, $P_{\text {RO }}$ ranges from 13 to 300 $\mathrm{kW}$ and the SEC ranges from 3.12 to $7.6 \mathrm{kWh} / \mathrm{m}^{3}$. By considering the variation of feed water salinity $X_{f}$ from 30000 
to $45000 \mathrm{ppm}$. The results of optimum values for $N_{v}, \mathrm{P}_{\mathrm{RO}}$ and the SEC are illustrated in Fig. 11 at $\mathrm{RR}=0.3$ and variable productivity up to $10000 \mathrm{~m}^{3} / \mathrm{d}$. Fig. 11(a) shows that $N_{v}$ ranges from 2 to 230 and from 2 to 160 when salinity is 30000 and $45000 \mathrm{ppm}$, respectively. This means that high salt concentration plants require less number of vessels to produce the same amount of fresh water. However, both $\mathrm{P}_{\mathrm{RO}}$ and SEC are relatively increased by increasing feed salinity due to increased pressure. As shown in Fig. 11(b), the power ranges from 18 to $1490 \mathrm{~kW}$ and 25 to $2480 \mathrm{~kW}$ at 30000 and 45000 ppm of feed salinity, respectively. While, the SEC is between 4 and $6.7 \mathrm{kWh} / \mathrm{m}^{3}$ at 30000 and $45000 \mathrm{ppm}$, respectively, as shown in Fig. 12(c).

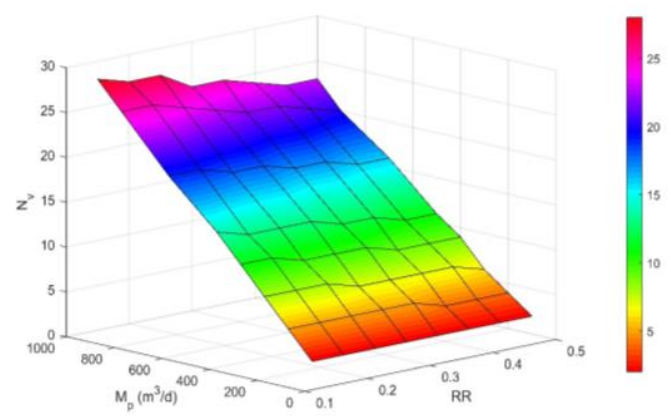

(a)

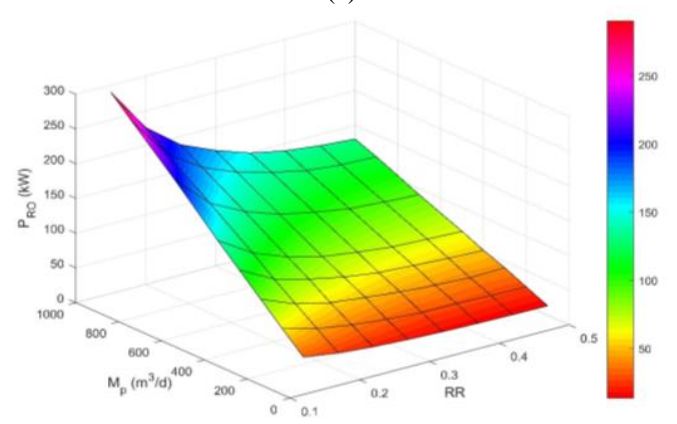

(b)

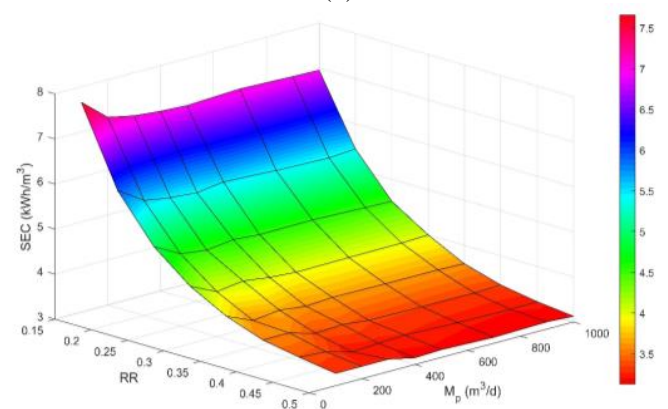

(c)

Fig. 10. Results of the optimum values for (a) $N_{v}$ (b) $\mathrm{P}_{\mathrm{RO}}$ and (c) SEC at $X_{f}=$ $30000 \mathrm{ppm}, 0.15 \leq R R \leq 0.5$ and $100 \leq M_{p} \leq 1000 \mathrm{~m}^{3} / \mathrm{d}$.

\section{E. PV-HWT Model Results}

The results of PV panel, wind turbine and battery specifications are summarized in Table I.

Based on the $250 \mathrm{~W}$ PV panel and $1000 \mathrm{~W} / \mathrm{m}^{2}$ solar irradiance, the model gives the main characteristics of the panel, its life time and cost. With respect to average wind speed of $11 \mathrm{~m} / \mathrm{s}$ in the site and $10 \mathrm{~kW}$ wind turbine power rating, the model provides the most suitable unit, its specifications, life time and cost. By simulating the model using these specified units under variable load conditions, it can calculate number of PV modules, number of wind turbines, total annual costs and the unit cost of fresh water.

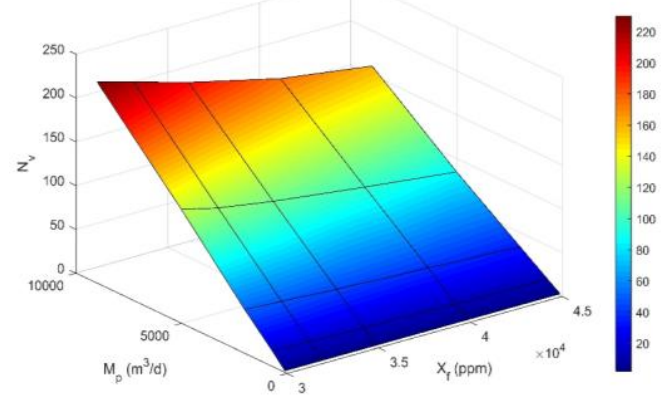

(a)

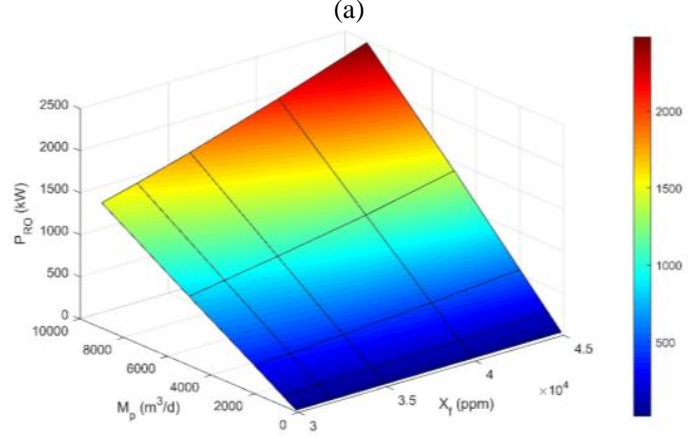

(b)

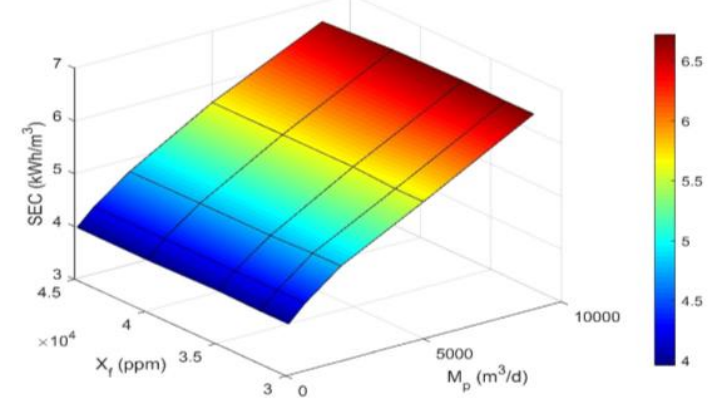

(c)

Fig. 11. Results of the optimum values for (a) $N_{v}$ (b) $\mathrm{P}_{\mathrm{RO}}$ and (c) $\mathrm{SEC}$ at $R R=$ $0.3,30000 \leq X_{f} \leq 45000 \mathrm{ppm}$ and $M_{p} \leq 10000 \mathrm{~m}^{3} / \mathrm{d}$.

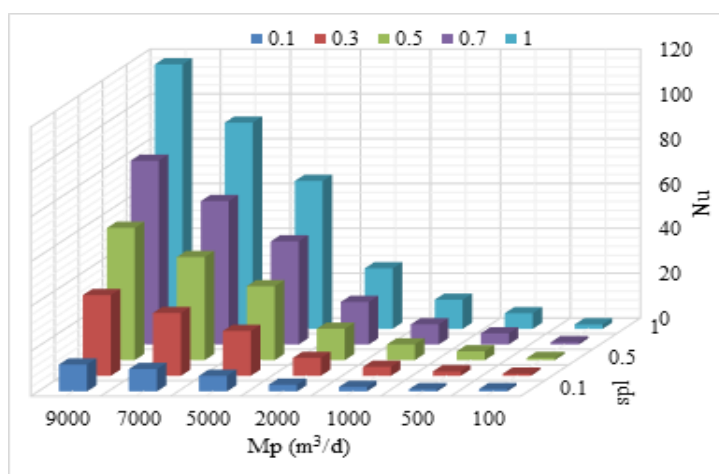

(a)

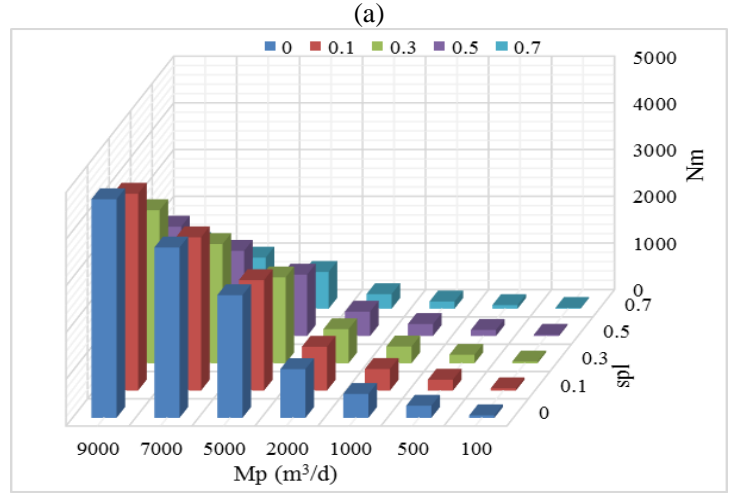

(b) 


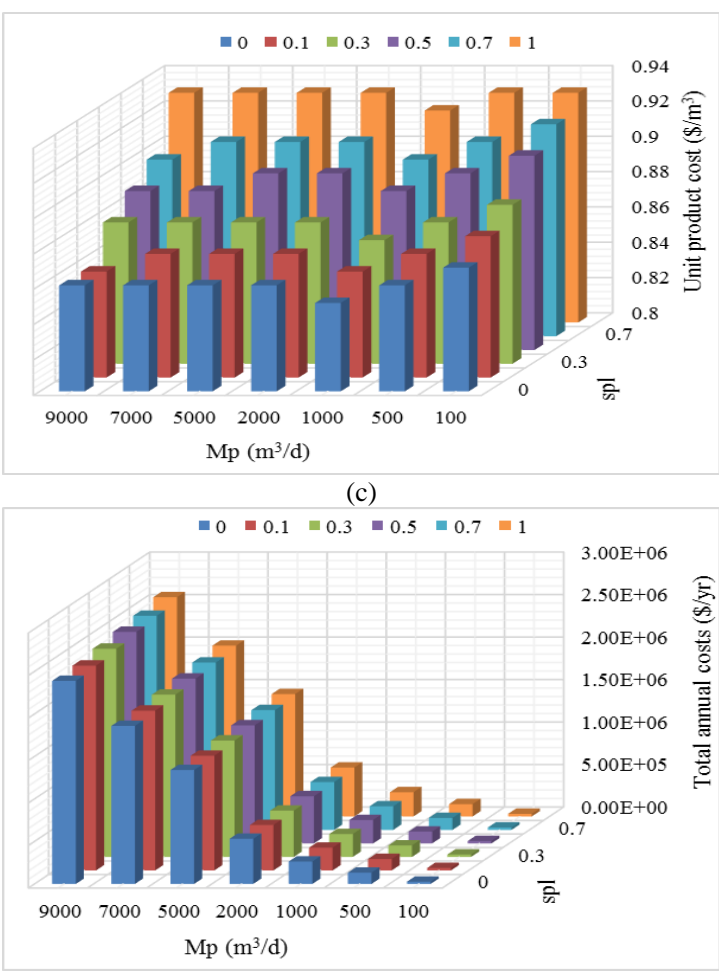

(d)

Fig. 12. Results of (a) number of wind turbines, (b) number of PV modules, (c) unit product cost and (d) total annual costs at variable load conditions and splitter ratio ranging from 0 to 1 when $X_{f}=30000 \mathrm{ppm}$ and $R R=0.5$.

TABLE I: SPECIFICATION RESULTS OF THE PV-WT MODEL

\begin{tabular}{c|c|c|c|c|c|c|c}
\hline \hline \multicolumn{1}{c}{$\begin{array}{c}\text { Podul } \\
\text { e } \\
\text { power } \\
\text { (W) }\end{array}$} & $\begin{array}{c}\text { Open } \\
\text { circuit } \\
\text { voltag } \\
\text { e (V) }\end{array}$ & $\begin{array}{c}\text { Short } \\
\text { circuit } \\
\text { current } \\
\text { (A) }\end{array}$ & $\begin{array}{c}\text { Voltage at } \\
\text { maximum } \\
\text { power (V) }\end{array}$ & $\begin{array}{c}\text { Current } \\
\text { at } \\
\text { maximu } \\
\text { m power }\end{array}$ & $\begin{array}{c}\text { Module } \\
\text { efficien } \\
\text { cy (\%) }\end{array}$ & $\begin{array}{c}\text { Unit } \\
\text { cost } \\
(\$)\end{array}$ & $\begin{array}{c}\text { Life } \\
\text { time } \\
(\mathrm{yr})\end{array}$ \\
\hline 250 & 37.7 & 8.85 & 30.5 & 8.2 & 15.3 & 250 & 20 \\
\hline \multicolumn{7}{c}{ WT unit specifications } \\
\hline $\begin{array}{c}\text { Unit } \\
\text { power } \\
(\mathrm{kW})\end{array}$ & $\begin{array}{c}\text { Cut-in } \\
\text { wind } \\
\text { speed } \\
(\mathrm{m} / \mathrm{s})\end{array}$ & $\begin{array}{c}\text { Max. } \\
\text { wind } \\
\text { speed } \\
(\mathrm{m} / \mathrm{s})\end{array}$ & $\begin{array}{c}\text { Rated AC } \\
\text { voltage (V) }\end{array}$ & $\begin{array}{c}\text { Hub } \\
\text { height } \\
(\mathrm{m})\end{array}$ & $\begin{array}{c}\text { Rotor } \\
\text { speed } \\
(\mathrm{rpm})\end{array}$ & $\begin{array}{c}\text { Unit } \\
\text { cost } \\
(\$)\end{array}$ & $\begin{array}{c}\text { Life } \\
\text { time } \\
(\mathrm{yr})\end{array}$ \\
\hline 10 & 3 & 11 & 220 & 9 & $0-400$ & 3000 & 20 \\
\hline
\end{tabular}

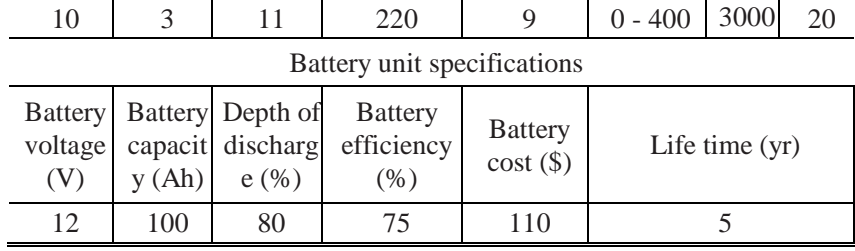

By varying the splitter control ratio (spl) from 0 to 1 , the load power fluctuates between the PV panels and the wind turbines. The economic results are shown in Fig. 12 under variable load capacity ranging from 100 to $10000 \mathrm{~m}^{3} / \mathrm{d}$. When $\mathrm{spl}=0$ (full PV loaded), the number of PV modules ranges from 55 to 4600 panels with total annual costs ranging from $2.7 \mathrm{e}+04$ to $2.4 \mathrm{e}+06 \$ / \mathrm{yr}$, and the unit product cost is about $0.86 \$ / \mathrm{m}^{3}$. However, at $\mathrm{spl}=1$ (full WT loaded), the number of wind turbines ranges from 2 to 120 unit with total annual costs ranging from $3 \mathrm{e}+04$ to $2.5 \mathrm{e}+06 \$ / \mathrm{yr}$, and the unit product cost is about $0.93 \$ / \mathrm{m}^{3}$. It can be seen from Fig. 12(c), that the unit product cost is very close to 0.86 and $0.93 \$ / \mathrm{m}^{3}$ for any amount of water production and different loading percentage. Also, the total annual costs are almost constant at constant capacity whether the load fluctuates between PV panels and wind turbines as shown in Fig. 12(d). For a reliable design, the splitter ratio should be chosen between 0 and 1 (hybrid PV and WT source) according to the weather conditions in the site and the land area available for PV modules and wind turbines.

\section{MODEL VALIDATION}

The developed model is validated by comparing the simulation results with the actual data of the desalination plant [6] in Matrouh, Egypt as a case study. The comparison show good results for power consumption, SEC and unit product cost as shown in Table II.

TABLE II: COMPARISON RESUlTS OF THE DEVELOPED MODEL WITH MATROUH PLANT

\begin{tabular}{c|c|c}
\hline \hline Variable & Matrouh plant & $\begin{array}{c}\text { Developed } \\
\text { model }\end{array}$ \\
\hline Plant capacity, $\mathrm{m}^{3} /$ day & \multicolumn{2}{|c}{1200} \\
\hline Feed salinity, ppm & \multicolumn{2}{|c}{34000} \\
\hline Recovery ratio & 5 & 6 \\
\hline Number of pressure vessels & 4 & 5 \\
\hline Number of elements/vessel & 35 & 284 \\
\hline Pressure, bar & 280 & 4.65 \\
\hline Power consumption, $\mathrm{kW}$ & 4.7 & 1.13 \\
\hline $\begin{array}{c}\text { Specific energy consumption, } \\
\mathrm{kWh} / \mathrm{m}^{3}\end{array}$ & 1.25 & \\
\hline Unit product cost, $\$ / \mathrm{m}^{3}$ & & \multicolumn{2}{|c}{0.45} \\
\hline \hline
\end{tabular}

\section{CONCLUSIONS}

A techno-economic study of a seawater reverse osmosis desalination plant fed by hybrid renewable PV and wind energy sources is presented. The main conclusions of this work are

- Studying the effect of different operating conditions such as feed salinity, recovery ratio and the number of pressure vessels on the specific energy consumption of the plant.

- Designing an optimization model which gives the optimum SEC based on the number of vessels and recovery ratio for a wide range of productivity from 100 to $10000 \mathrm{~m} 3 /$ day and different feed salts concentration.

- Designing a new model for PV panels and wind turbines based on the storage of various manufacturing datasheets of different PV panels and WT power ratings. The model calculates the total annual costs under variable load conditions and the cost of fresh water production.

- Regulating the power distribution between PV and WT sources using the splitter control ratio.

- Validating the model by comparing the simulation results with the actual data of Matrouh desalination plant.

\section{CONFLICT OF INTEREST}

The authors declare no conflict of interest.

\section{AUTHOR CONTRIBUTIONS}

Ahmed A. Hossam-Eldin and Kamal Abed analyzed the data while Karim H. Youssef and Hossam Kotb made the experimental work and wrote the paper. All authors had 
approved the final version

\section{REFERENCES}

[1] A. Lamei, P. Zaag, and E. Münch, "Basic cost equations to estimate unit production costs for RO desalination and long-distance piping to supply water to tourism-dominated arid coastal regions of Egypt," Desalination, vol. 225, pp. 1-12, 2008.

[2] A. Nafey and M. Sharaf, "Combined solar organic Rankine cycle with reverse osmosis desalination process: Energy, exergy, and cost evaluations," Renewable Energy, vol. 35, pp. 2571-2580, 2010.

[3] M. Wilf and C. Bartels, "Optimization of seawater RO systems design," Desalination, vol. 173, pp. 1-12, 2005.

[4] G. Kyriakarakos, A. Dounis, K. Arvanitis, and G. Papadakis, "Design of a fuzzy cognitive maps variable-load energy management system for autonomous PV-Reverse osmosis desalination systems: A simulation survey," Applied Energy, vol. 187, pp. 575-584, 2017.

[5] D. Zejli, A. Ouammi, R. Sacile, H. Dagdougui, and A. Elmidaoui, "An optimization model for a mechanical vapor compression desalination plant driven by a wind/PV hybrid system," Applied Energy, vol. 88, pp 4042-4054, 2011.

[6] A. Hossam-Eldin, A. Elnashar, and A. Ismaiel, "Investigation into economical desalination using optimized hybrid renewable energy system," Elec. Power and Energy, vol. 43, pp.1393-1400, 2012.

[7] M. Laissaoui, P. Palenzuela, M. Sharaf, D. Nehari and D. Alacron-Padilla, "Techno-economic analysis of a stand-alone solar desalination plant at variable load conditions," Applied Thermal Engineering, vol. 133, pp. 659-670, 2018.

[8] E. Mohamed, G. Papadakis, E. Mathioulakis, and V. Belessiotis, "A direct coupled photovoltaic seawater reverse osmosis desalination system toward battery-based systems-a technical and economical experimental comparative study," Desalination, vol. 221, pp. 17-22, 2008.

[9] A. Helal, S. Al-Malek, and E. Al-Katheeri, "Economic feasibility of alternative designs of a PV-RO desalination unit for remote areas in the United Arab Emirates," Desalination, vol. 221, pp. 1-16, 2008.

[10] D. Manolakos, E. Mohamed, I. Karagiannis, and G. Papadakis, "Technical and economic comparison between PV-RO system and RO-Solar Rankine system. Case study: Thirasia island," Desalination, vol. 221, pp. 37-46, 2008.

[11] G. Ahmad, and J. Schmid, "Feasibility study of brackish water desalination in the Egyptian deserts and rural regions using PV systems," Energy Conversion and Management, vol. 43, pp. 2641-2649, 2002.

[12] E. Tzen, K. Perrakis, and P. Baltas, "Design of a standalone PV-desalination system for rural areas," Desalination, vol. 119, pp. 327-334, 1998

[13] C. Liu, W. Xia, and J. Park, "A wind-driven reverse osmosis system for aquaculture wastewater reuse and nutrient recovery," Desalination, vol. 202, pp. 24-30, 2017.

[14] I. Pestana, F. Latorre, C. Espinoza, and A. Gotor, "Optimization of RO desalination systems powered by renewable energies. Part I: Wind energy," Desalination, vol. 160, pp. 293-299, 2014

[15] D. Dehmas, N. Kherba, F. Hacene, N. Merzouk, M. Merzouk, H. Mahmoudia, and M. Goosen, "On the use of wind energy to power reverse osmosis desalination plant: A case study from Ténès (Algeria)," Ren. and Sust. Energy, vol. 15, pp. 956-963, 2011.

[16] L. Rodríguez, V. Ternero, and C. Camacho, "Economic analysis of wind-powered desalination," Desalination, vol. 137, pp. 259-265, 2011.

[17] V. Romero, L. García, and C. Gómez, "Thermoeconomic analysis of wind powered seawater reverse osmosis desalination in the Canary Islands," Desalination, vol. 186, pp. 291-298, 2005.

[18] A. Nafey, M. Sharaf, and L. Rodríguez, "Thermo-economic analysis of a combined solar organic rankine cycle-reverse osmosis desalination process with different energy recovery Configurations," Desalination, vol. 261, pp. 138-147, 2010.

Copyright $\odot 2019$ by the authors. This is an open access article distributed under the Creative Commons Attribution License which permits unrestricted use, distribution, and reproduction in any medium, provided the original work is properly cited (CC BY 4.0).

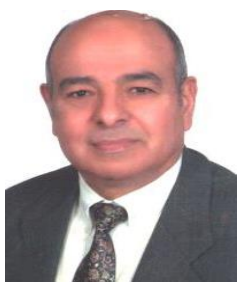

Ahmed A. Hossam-Eldin got his B.Sc (EE) distinction with honors, the M.Sc from Alexandria University on 1965 and 1969 respectively and the Ph.D from Heriot-Watt University, Edinburgh, U.K on 1972, where he worked as a staff member. He was promoted to Professor of Electrical Materials and Power Engineering in Alexandria University. His fields of interest are: electromagnetic interference, cryogenic \& superconducting cables, partial discharges, and breakdown in dielectrics, distribution systems, renewable energy, biomass and biodiesel, utilization of renewable energy in desalination, cathodic protection and lightning protection. He published more than 300 articles in top refereed journals and published 5 books. He patented some of his work. He received top national and international awards for his contribution to his society and the achievement to the world. He supervised 135 Postgraduate students for Ph.D and M.Sc. He is the PI for 30 research projects. He was a visiting professor to Universities in France, Southampton, Edinburgh, Zimbabwe, King Abdelaziz (S.A), Kuwait and Philips Dodge Cable co. USA.

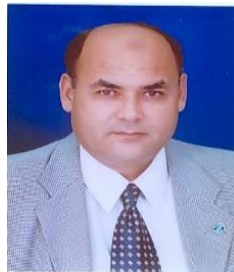

Kamal A. Abed was born in Giza, Egypt, on January 14, 1955. He received the B.Sc. degree from Suez Canal University, Egypt, the M.Sc. degree from Cairo University, Egypt, and the Ph.D. degree from Warsaw University of Technology, Poland, in mechanical power engineering in 1978, 1986, and 1991 , respectively. He is a professor of power and energy in 2002. From 2003 to 2010, He was the head of Mechanical Engineering Department, National Research Centre (NRC), Cairo, Egypt. He was the chair of Energy Resources and Environmental Engineering Department, Egypt-Japan University of Science and Technology (E-JUST), Alexandria, Egypt in 2010. He was the head of Scientific Instruments Centre, Cairo, from 2010 to 2015. From 2012 to 2015 , He was the head of Engineering Research Division, National Research Centre (NRC), Cairo, Egypt. He is currently an Emeritus Professor of Power and Energy, in the Mechanical Engineering Department, NRC, Cairo, Egypt.

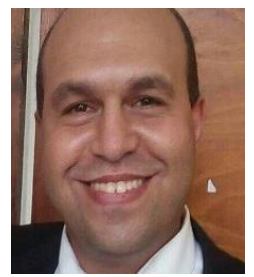

Karim H. Youssef received the B.Sc., M.Sc., and $\mathrm{Ph} . \mathrm{D}$. degrees in electrical engineering from Alexandria University, Alexandria, in 2003, 2005, and 2009 , respectively. $\mathrm{He}$ is an associate professor in the Electrical Engineering Department, Faculty of Engineering, Alexandria University. His current research interests include power system design, control and automation, power electronics applications, renewable energy, and smart grid. Dr. Youssef was the recipient of the Egyptian Government Award for his Ph.D. dissertation.

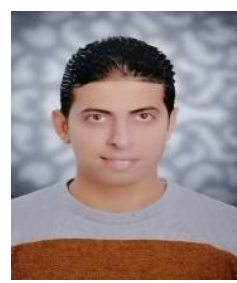

Hossam Kotb received the B.Sc. and M.Sc. degrees in electrical engineering from Alexandria University, Alexandria, Egypt in 2009 and 2013, respectively. $\mathrm{He}$ is currently a teaching assistant in the Electrical Engineering Department, Faculty of Engineering, Alexandria University. $\mathrm{He}$ is currently working toward the Ph.D. degree in electrical engineering and his research interests include renewable energy, smart grid, industrial process design, desalination, control and automation. 